\title{
TRÊS TEMPOS DE CARIDADE, ASSISTÊNCIA E FILANTROPIA EM GOIÁS (SÉCULOS XVIII AO XX)
}

\section{Three times of charity, assistance and philanthropy in Goiás (Centuries XVIII to XX)}

\author{
Cristina de Cássia Pereira Moraes* \\ Lara Alexandra Tavares" \\ Rildo Bento de Souza ${ }^{* *}$
}

\begin{abstract}
RESUMO
O objetivo do presente artigo é analisar a produção historiográfica classificada, como História da Assistência em Goiás e, de forma sucinta e exploratória; expor os pressupostos e interpretações conceituais sobre o medo como o gerador impulsionador da caridade e o assistencialismo a pobreza, a caridade e a filantropia segundo as pesquisas realizadas desde a antiga capital Vila Boa à moderna e atual Goiânia. Em um primeiro momento, apresentaremos o significado dos termos caridade e associações interligados às irmandades no século XVIII e XIX. Por último, buscaremos entender a Sociedade São Vicente de Paula e o Orfanato São José como instituições de caridade e filantropia em fins do dezenove até meados do século $\mathrm{XX}$.
\end{abstract}

Palavras-chave: caridade; filantropia; assistencialismo

\begin{abstract}
The objective of this article is to analyze the classified historiographic production, as History of Assistance in Goiás and, in a succinct and exploratory way; to expose the presuppositions and conceptual interpretations about poverty, charity,

\footnotetext{
* Professora Associada da Faculdade de Historia da Universidade Federal de Goiás.

** Mestre em Historia pela Universidade Federal de Goiás.

*** Doutor em História. Professor Adjunto da Faculdade de Ciências Sociais da Universidade Federal de Goiás.
} 
philanthropy and welfarism according to research carried out from the old capital of Vila Boa to modern and modern Goiânia. In a first moment, we will present the meaning of the terms charity and associations interrelated to the brotherhoods in the eighteenth and nineteenth centuries. Finally, we will try to understand from the religiosity a whole new world at the end of the nineteenth until the middle of the XX century. the one of the philanthropy and the one of the charity.

Keywords: charity; philanthropy; welfarism

\section{Introdução}

O milenarismo influencia a sociedade cristã desde o ano IV antes de nossa era e do atual calendário gregoriano. A escatologia que assolou a população mundial no primeiro milênio impera desde o século XVIII entre os miseráveis, os pobres e a elite letrada ou não. Muitos ainda acreditam - principalmente após o fim do segundo milênio - que os sinais bíblicos apontados no Apocalipse de João estão presentes na miséria reinante, nas doenças recalcitrantes, na nova ordem econômica, na eminência de uma terceira guerra mundial, na destruição da camada de ozônio, na extinção de inúmeras espécies de animais, no imigrante, no refugiado, na intolerância religiosa, na homossexualidade, no diferente, dentre outros. É "quase" um dèja vu ao fim do primeiro milênio quando "a besta seria libertada de suas correntes e o Anticristo estaria a viver entre nós". O termo anticristo ocorre apenas quatro vezes na Bíblia, todas elas nas cartas do apóstolo João. As passagens são $1^{\circ}$ João 2:18 , 2:22, 4:3 e $2^{\circ}$ João 1:7, onde o termo anticristo é definido como um "espírito de oposição" aos ensinamentos de Cristo ${ }^{1}$. O medo passou a imperar, e uma esperança por dias melhores, para além de uma procura por seitas e crenças mais convincentes no período pós-apocalíptico e em céus e

1 Existe ampla discussão sobre a temática do milenarismo, sugerimos: DUBY, Georges. Ano 1000, ano 2000. Na pista de nossos medos. São Paulo: Ed. Unesp, 1999; 
purgatórios mais acessíveis, com deuses e santos brandos e menos exigentes é o que tem feito mais sucesso na mídia e em redes sociais.

\section{As Irmandades}

Por conseguinte, este trabalho abordará o assistencialismo e a filantropia, porém, vistos sob a perspectiva da caridade desencadeada pelo medo. O medo abordado desde meados do século XVIII será principalmente o medo de morrer e de não se ter preparado para a mesma; ou seja, o de ter tido uma boa morte. Para isso, bastava contar com uma irmandade, confraria, ordem terceira ou uma pia-união. À partida, há que se ter presente, que o Código do Direito Canônico divide as associações em Ordens Terceiras, irmandades, confrarias e pias uniões. As primeiras, sob a inspiração e a orientação duma determinada Ordem ou Congregação religiosa, cuja Regra tem aprovação eclesiástica e como preocupação fundamental a perfeição da vida cristã de seus associados, os quais são genericamente chamados de terceiros e, igualmente, vivenciam mais intensamente as Obras de Misericórdia.

Quando os fiéis se associam para fazer alguma obra de piedade ou caridade, essa associação recebe o nome de pia união. Se essa associação, por sua vez, tem ainda uma hierarquia, é designada por irmandade. Seus membros, irmãos ou confrades, segundo o Compromisso, também assumem o dever de se auxiliar reciprocamente, tendo, pois, sob esse aspecto, uma identificação de ideais e interesses comuns entre os membros e os candidatos a ingressarem na mesma e uma seleção prévia e restrita dos mesmos, com vista a agregá-los mais facilmente, bem como ainda a evitar fissuras em seu interior. Ambas as modalidades de associação, portanto, têm um perfil assistencialista. Se as irmandades são eretas para incrementar o culto público de um santo, recebem o nome de 
confrarias $^{2}$. Do que afirmamos, e, sobretudo da prática, as Irmandades e as Confrarias acabam por exercer uma função cumulativa. Isto é, Irmandades com fins, também, devocionais e Confrarias, também, com fins assistenciais. Portanto, resulta daqui, a dificuldade em definir, não legalisticamente, mas efetivamente, Irmandades e Confrarias.

Do exposto, podemos definir irmandades como associações cujo objetivo era o de congregar as pessoas, que escolhendo um santo protetor comum, passariam a contar com sua protecção especial em meio às lutas terrenas. $\mathrm{O}$ compromisso mútuo era o de promover e manter a devoção ao orago dentro de um determinado espaço, não apenas formal ou concreto como capelas e igrejas, mas também como espaço mental que se constituiria quase como um espelho da sua autoimagem, de sua identidade como grupo. Pode-se resumir as principais finalidades ou objetivos das associações religiosas, associações beneficentes e conferencias afirmando que, a par das atividades assistenciais aos seus membros, por exemplo, a criação e manutenção de hospitais, hospícios, asilos e orfanatos, e até mesmo, o auxílio financeiro para os funerais e para casamento, elas também os assistiam no âmbito de vida espiritual ou religiosa, verbi gratia, estimulando-os a participar das missas e festas de guarda da Igreja Romana, determinando cuidarem das celebrações em louvor do seu orago, a participarem das reuniões da mesma associação, quando fosse o caso, a cumprirem as suas demais normas estatutárias e, até mesmo, prepará-los, quando possível, para morrer bem.

Morrer bem significa não ter tido medo, porque foi um homem de fé e caridoso. Após ter cumprido com seus deveres de um dizimeiro e vassalo fiel, um devoto filho e irmão de algum santo em uma irmandade eis que, após a confissão e o testamento, pode descansar em paz com a ajuda de outros irmãos.

A respeito do medo da punição devemos observar três aspectos: quem são os purgados, por quem são purgados, onde são purgados. Os que são purgados dividem-se em três categorias. Os primeiros são os que morrem sem ter feito a penitência que lhes cabia. Miguelez Domingues et al. Madri: La Editorial Católica, 1947, p.281. 
Se por ventura, tivesse no coração a contrição para apagar seus pecados, passariam livremente para a vida eterna mesmo não tendo realizado nenhuma reparação. Mas, aos que morreram sem se arrependerem, ou antes, de completar alguma penitência, são severamente punidos no fogo do purgatório, a menos que os vivos fiquem encarregados de sua reparação. Para que tal reparação tenha valor, são necessárias quatro condições.

A primeira é que deve ser autorizada pelos padres; a segunda diz respeito quando o beneficiário não pode estar em condições de reparação; a terceira é quando o reparador tem caridade meritória suficiente; a quarta é quando existe a proporção entre a reparação e a pena, de maneira que uma menor seja comutada por uma maior; pois satisfaz mais a Deus a pena sofrida pessoalmente do que por outrem. Há três tipos de penas; a pessoal e voluntária - tem maior poder de reparação - a pessoal e não voluntária - é sofrida no Purgatório - a voluntária, mas não pessoal - é objeto de reparação, mas, satisfaz menos por não ser pessoal como a primeira e mais que a segunda por ser voluntária. Portanto, para se livrar das penas, o fiel necessita dos sufrágios feitos pelos amigos e familiares. Há quatro tipos de sufrágios deveras vantajosos para os mortos: a prece dos fieis, a prática da esmola, a celebração da missa e a observação do jejum. Os mais utilizados foram as missas com variações na quantidade dependendo da época.

O importante é contar com a caridade dos irmãos que irão rezar para os que se foram. Não interessa saber se você conhecia o mesmo, mas a missa em intenção do defunto ou para as almas do purgatório era para ser rezada por quem lá estava ou não! Como saber? "Fazer o bem sem olhar a quem! Gálatas cap.6 vers. 10. 


\section{A Sociedade São Vicente de Paulo}

A Sociedade São Vicente de Paulo em Goiás, nos seus pedidos de contribuição para a população vilaboense, sempre colocava algumas frases de efeito para sensibilizar as pessoas a fazerem suas doações, tais como: "o pobre é nossa riqueza", ou "quem dá aos pobres, empresta a Deus". Essa relação evidencia a forma como a caridade era entendida: a caridade como meio para se obter algo de Deus, a quem é devedor de indulgências aos que ajudam os pobres, que, por sua vez, é a "riqueza" dos que os ajudam, já que com isso podem exercitar a caridade.

Nos jornais e até mesmo no cemitério, os doadores queriam ver "estampada" as suas ações, como forma de publicidade para, além do reconhecimento pessoal, incentivar tais iniciativas. Em 19 de agosto de 1909, o jornal $O$ Lidador, que pertencia a Diocese, anunciava a doação para uma das obras da Sociedade São Vicente de Paulo, o asilo, "a esmola de $100 \$ 000$ rs. Nossos parabens ao generoso vicentino pela bellaacção que vem de praticar, almejando que ella encontre imitadores"4. Em outro caso, 02 de novembro de 1909, encontramos noticiário similar: "Para o Asylo S. Vicente de Paulo, desta Capital, deu o sr. [...], a esmola de $20 \$ 000$. Nossos parabens ao generoso doador"5. No cemitério da cidade, em uma lápide de 1902 ainda resiste o epitáfio: "Restos mortaes do caridozo capitão (...)"6. A caridade ganhava um viés exibicionista, contrariando a própria lógica Cristã, detalhado no Evangelho de Mateus, capítulo 06, versículos de 1 a 4 :

4 Gabinete Literário: Documentos Avulsos. O Lidador. Ano VI - n .32 . Cidade de Goiás, 1909, p. 02.

5 Gabinete Literário: Documentos Avulsos. O Lidador. Ano VI - n. 34. Cidade de Goiás 1909, p. 02.

6 Cemitério da Cidade de Goiás. "Restos Mortaes do Caridozo Capitão Antonio Manoel Gomes da Neiva. Fallecido a 15 de Agosto de 1902 com 63 Annos de Idade”. Cidade de Goiás, 1902. 
Guardai-vos de fazer a vossa esmola diante dos homens, para serdes vistos por eles; aliás, não tereis galardão junto de vosso Pai, que está nos céus.

Quando, pois, deres esmola, não faças tocar trombeta diante de ti, como fazem os hipócritas nas sinagogas e nas ruas, para serem glorificados pelos homens. Em verdade vos digo que já receberam o seu galardão.

Mas, quando tu deres esmola, não saiba a tua mão esquerda o que faz a tua direita;

Para que a tua esmola seja dada em secreto; e teu Pai, que vê em secreto, ele mesmo te recompensará publicamente. $^{7}$

Diante do exposto, podemos chamar os vicentinos de filantropos, ao invés de caridosos? A linha entre esses dois conceitos, vistos na sociedade vilaboense no decorrer da Primeira República, é muito tênue. De acordo com o estudo de Gisele Sanglard, enquanto a caridade seria visto como algo cristão, a filantropia, por outro lado, “(...) seria uma virtude social e seu desenvolvimento estaria ligado ao papel desempenhado pelos filósofos das Luzes no final do Antigo Regime”. Nesse sentido, os filantropos “(...) buscaram esvaziar o caráter caritativo da filantropia reforçando seu lado de utilidade social, e o termo passou a ser percebido mais como prevenção à miséria do que uma forma de suavizá-la" 8.

A intenção da Sociedade São Vicente de Paulo, desde a sua criação na França, era a de suavizar a pobreza, contribuir com donativos materiais, seja comida, roupa, aluguel de casas, dentre outros. Os filantropos, por sua vez, não doavam simplesmente, ofereciam trabalho, e encorajavam a população para a produção. A grande diferença entre caridade e filantropia é que a primeira se baseava na piedade, ou seja, pressupunha “(...) a abdicação de toda a vaidade de seu autor e propugna o anonimato, ao passo que a segunda é marcada por um gesto de utilidade, e neste caso a publicidade se

7 Bíblia Sagrada. Mateus, capítulo 6, versículo de 1 a 4.

8 SANGLARD, Gisele Porto. Entre os salões e o laboratório: Filantropia, mecenato e práticas científicas. Rio de Janeiro, 1920-1940. Tese (Doutorado em História das Ciências da Saúde). Rio de Janeiro: Casa de Oswaldo Cruz - FIOCRUZ, 2005, p. 29. 
torna uma arma importante nas mãos dos filantropos, além de acirrarlhes a rivalidade" .

$\mathrm{O}$ fato de que a caridade pressupõe o anonimato e a filantropia seria, por sua vez, aberto a manifestações publicitárias em torno do ato de doar, torna os Vicentinos e todos aqueles que doavam para a Sociedade São Vicente de Paulo, e que ostentavam o seu feito pela imprensa, filantropos. Entretanto, o objetivo dos Vicentinos não era erradicar a pobreza a longo prazo por instrumentos que ensejassem isso, como o incentivo ao trabalho, por exemplo; era apenas o de angariar recursos para prover os pobres em tudo que necessitassem. Essa rede de assistência, ora ou outra, teria que contar com o apoio da sociedade, pois somente os seus membros não conseguiriam sustentar todos os pobres. Por isso que nos seus pedidos de doação, frases de efeito, como a que citamos no início desse tópico, e um texto emotivo sensibilizavam a comunidade e eram sempre utilizados.

Deste modo, embora, a primeira vista, as atitudes dos vicentinos, principalmente em relação à publicidade e exaltação de seus atos de doação, os coloquem mais como filantropos, iremos usar o conceito que eles se usavam para se referirem a si próprios e os outros, e que levavam até mesmo para perpetuar numa lápide de mármore: caridosos.

Desde a Idade Média, o interesse em ajudar os pobres sob o discurso cristão, era "não era apenas moral - também era espiritual". Por que ter "seus pobres, tal como se tinha seus mansos e seus criados, também significava ter seus intercessores, com o objetivo de redimir seus pecados e ter sua salvação garantida" ${ }^{10}$. Para além da publicidade e do reconhecimento, a caridade da Sociedade São Vicente de Paulo em Goiás visava intermediar uma relação com Deus.

Fundada em Paris em 23 de abril de 1833, por um jovem estudante chamado Frederico de Ozanam (1813-1853), batizou com o nome do santo francês, a sua sociedade de leigos que se organizavam

9 Idem, p. 30.

149.

10 MOLLAT, Michel. Os Pobres na Idade Média. Rio de Janeiro: Campos, 1989, p. 
em conferências, com número determinado de participantes que se reunião sob a proteção de um orago, com o objetivo de ajudar os pobres $^{11}$. Ao comparar a biografia de Ozanam com a hagiografia de São Vicente de Paulo (1581-1660) o estudo de Souza observou "ênfases diferentes na operacionalização prática do que vem a ser a caridade". Para o "primeiro a ênfase era o conforto espiritual, tendo o auxílio material somente em períodos de muita carência; a ênfase do segundo, por sua vez, centrava-se na prática da caridade por meio de auxílio material" ${ }^{\prime 2}$.

Atualmente, a Sociedade São Vicente de Paulo está presente em 135 países, com um número aproximado de 500 mil membros. $\mathrm{O}$ Brasil é o maior país vicentino do mundo: são 20 mil Conferências, 1754 Conselhos Particulares, 272 Conselhos Centrais, 30 Conselhos Metropolitanos e 2 mil Obras Unidas, coordenados pelo Conselho Nacional do Brasil. A Conferência de São José foi a primeira fundada no Brasil, no Rio de Janeiro, em 1872. Em Goiás, a "Sociedade de S. Vicente de Paulo ennunciou-se em nossa Província pela fundação da $1^{\text {a }}$ Conferencia que foi installada no dia 29 de Abril de $85 \mathrm{com}$ desesete sócios" ${ }^{\prime 13}$.

A criação das Conferências da Sociedade São Vicente de Paulo fazia parte de um grande projeto de retomada do catolicismo em terras brasileiras, chamado romanização ${ }^{14}$. Ademais, uma das primeiras medidas impostas pela Reforma Ultramontana, como também era conhecida, foi a substituição do leigo, que perde, deste modo, a sua autonomia religiosa, que passaria a ter validade com a aprovação do clero. Assim, as Irmandades religiosas fundadas e

11 A Sociedade São Vicente de Paulo estrutura-se da seguinte forma: as Conferências de determinada cidade estão unidas entre si pelos Conselhos Particulares. Estes, por sua vez, estão vinculados aos Conselhos Centrais, de caráter executivo, que responde por determinada circunscrição. Na sequência hierárquica há os Conselhos Metropolitanos, de âmbito regional. Em nível nacional, existe o Conselho Nacional do Brasil, com sede no Rio de Janeiro, RJ. Coordenando o trabalho em todo mundo está o Conselho Geral Internacional, em Paris, na França.

12 SOUZA, Rildo Bento de. Pobreza, doenças e caridade em Goiás: uma análise do Asilo São Vicente de Paulo (1909-1935). Jundiaí-SP: Paco Editorial, 2014, p. 32.

13 Asilo São Vicente de Paulo, doravante denominado ASVP: Documentos Avulsos. Relatório do Conselho Particular da Sociedade São Vicente de Paulo enviado ao Conselho Central. Cidade de Goiás, 1888.

14 Sobre esse assunto ver: PEREIRA, Mabel Salgado. Romanização e Reforma Católica Ultramontana da Igreja de Juiz de Fora: projeto e limites (1890-1924). Dissertação (Mestrado em História). Rio de Janeiro: Universidade Federal do Rio de Janeiro, 2002. 
dirigidas por leigos sob a proteção de um orago tradicional, como Nossa Senhora do Rosário dos Homens Pretos, São Benedito, dentre outros, foram substituídas por associações leigas voltadas para os demais santos então em voga na Europa, como, por exemplo, São Vicente de Paulo e Nossa Senhora das Graças ${ }^{15}$. É neste período de transformações intensas no modus operandi do catolicismo que a Sociedade São Vicente de Paulo ganha espaço, não somente em Goiás, mas em todo o país.

Na Cidade de Goiás, os vicentinos formaram quase uma dezena de conferências nas primeiras décadas de funcionamento. Cada Conferência cuidava de certo número de pobres. Os Vicentinos forneciam os vales em dinheiro, ou gêneros alimentícios, roupas, dentre outros, e depois recebiam o respectivo valor do tesoureiro da Conferência ${ }^{16}$. A relação dos Vicentinos com os pobres era muito próxima. Na Conferência da Imaculada Conceição, por exemplo, no dia 28 de novembro de 1888 , um confrade requereu do tesoureiro treze mil e quinhentos réis proveniente da compra de roupa para "meu pobre,"17. Ou seja, cada confrade vicentino era responsável por determinado número de pobres. Para ser ajudado pela Sociedade São Vicente de Paulo os únicos requisitos eram ser pobres e católicos.

O pobre é aquele que, de modo permanente ou temporário, encontra-se em situação de debilidade, dependência e humilhação, caracterizada pela privação de meios, variáveis segundo as épocas e as sociedades, que garantem força e consideração social: dinheiro, relações, influência, poder, ciência, qualificação técnica,

15 SANTOS, Edivaldo Antônio dos. Os Dominicanos em Goiás e Tocantins. 18811930. Fundação e Consolidação da Missão Dominicana no Brasil. Dissertação (Mestrado em História). Goiânia: Universidade Federal de Goiás, 1996, p. 70.

16 No livro de recibos os confrades escreviam a quantia recebida do tesoureiro e onde haviam gasto o dinheiro, seguindo o modelo: "Recebi do Snr. Josino do Nascimento Marques Fogaça, thezoureiro da Conferencia da Immaculada Conceição, a quantia de doze mil e quinhentos importancia de 15 vales q forneci a tres pobres da mesma Conferencia e por ser verdade passa o presente em que firmo. Goyaz $1^{\circ}$ de Setembro de 1888. Lourenço Alves Costa" (ASVP: Documentos Avulsos. $1^{\circ}$ Livro de recibos das quantias pagas pelo thezoureiro da Conferencia da Immaculada Conceição. Cidade de Goiás, 1888-1889).

17 ASVP: Documentos Avulsos. $1^{\circ}$ Livro de recibos das quantias pagas pelo thezoureiro da Conferencia da Immaculada Conceição. Cidade de Goiás, 1888-1889. 
honorabilidade de nascimento, vigor físico, capacidade intelectual, liberdade e dignidade pessoais. Vivendo no dia-a-dia, não tem qualquer possibilidade de revelar-se sem a ajuda de outrem. Uma tal definição pode incluir todos os frustrados, todos os enjeitados, todos os associais, todos os marginais; ela não é específica de época alguma, de região alguma, de meio algum ${ }^{18}$.

Na hierarquia da pobreza, temos os mendigos, que estavam abaixo dos pobres, pois eram "reduzidos à mendicância por força do aprofundamento da situação de pobreza"19. E também, por último, o indigente, aquele "que até do necessário tem falta", que dependiam em tudo da ajuda alheia ${ }^{20}$. Tanto pobres, mendigos e indigentes, desde que católicos, eram ajudados pela Sociedade São Vicente de Paulo. Eles recebiam o conforto material por meio de dinheiro, comida, roupas, aluguel de casas, e patrocínio de casamentos (principalmente entre os amancebados), até noções de higiene para combater as doenças e evitar as epidemias, como a de varíola em 1904 e a de Gripe Espanhola, em 1918.

A partir de 1888, além do trabalho de cada Conferência, a Sociedade São Vicente de Paulo passou a centrar-se em quatro obras principais: a Escola Noturna, a Obra dos Enterros, a Doutrina Cristã e as Visitas à prisão e ao hospital. A primeira, a Escola Noturna, era a que mais se assemelhava a uma obra digna de um filantropo, já que tinha o objetivo de "produzir bons cidadãos" por meio da "instrucção dos pobres"; "foi mantida pelo Conselho Particular por espaço de um anno, vencendo a Sociedade grandes obstáculos para poder manter uma obra com que não fazia pequena despesa". Devido aos insistentes pedidos dos Vicentinos, o Governo Provincial fundou uma escola noturna no "mesmo predio em que funccionava a nossa, as mesmas horas e com os mesmos regulamentos, o que foi para nós de grande

18 MOLLAT, Michel. Os Pobres na Idade Média. Rio de Janeiro: Campos, 1989, p. 05. 19 FRAGA FILHO, Walter. Mendigos, Moleques e Vadios na Bahia do Século XIX. São Paulo, SP/Salvador, BA: Editora Hucitec/EDUFBA, 1996, p. 41.

20 PINTO, Luiz Maria da Silva. Diccionario da Lingua Brasileira. 1832. Edição FacSimilar. Goiânia: Sociedade Goiana de Cultura, Instituto de Pesquisas e Estudos Histórico do Brasil Central, Centro de Cultura Goiana, 1996. 
contentamento, pois vemos assim a obra de Deus com mais força e mais estabilidade" ${ }^{21}$. Entretanto, como a instrução não era vista no período como forma de ascensão social, o projeto foi abortado pouco tempo depois por falta de alunos ${ }^{22}$. Há que se ressaltar que a escola criada pelo governo funcionava no mesmo prédio, no mesmo período e mantendo o mesmo regulamento, que acreditamos seja pautada nos princípios católicos. Outrossim, nos relatórios dos presidentes de província, só encontramos uma menção à escola noturna ${ }^{23}$.

A obra dos enterros era uma das mais significativas da Sociedade São Vicente de Paulo. Consistia em uma carroça fechada, chamado de carro fúnebre, puxada por um cavalo, que transportava o esquife até o cemitério. Como os pobres não tinham condições de possuir um caixão, havia apenas um, que era utilizado pelo defunto durante o velório e o cortejo até o cemitério. O defunto era colocado na sepultura apenas com uma mortalha, e carro e o caixão eram recolhidos até a próxima utilização ${ }^{24}$. Até então a função de enterrar gratuitamente os indigentes era desempenhada pelo Hospital de Caridade São Pedro de Alcântara, “(...) instituição que abarcava funções e princípios caritativos cristãos" $" 25$.

A Doutrina Cristã ${ }^{26}$, por sua vez, inicialmente era de responsabilidade dos vicentinos, depois passou a cargo dos padres Dominicanos "que a elles declinamos de muito bom gosto, pois, infelismente, podemos com franqueza dizer que mais serviamos para

21 ASVP: Documentos Avulsos. Relatório do Conselho Particular da Sociedade São Vicente de Paulo enviado ao Conselho Central. Cidade de Goiás, 1888.

22 Foi somente com a Escola de Aprendizes e Artífices, criada na Cidade de Goiás em 1909 é que houve uma tentativa de criação de curso noturno para profissionalização dos pobres, mas que não foi avante, porque os próprios pobres não viam nelas nenhum significado prático. Para serviços braçais não precisavam ser alfabetizados.

23 A única alusão sobre a mesma foi localizada no relatório do Sr. Dr. Fulgêncio Firmino Simões, datado de 1888, quando se aborda a questão da nomeação de professores: "para a noturna da capital o cidadão José Gomes dos Santos (...)”. In: Relatório com que o Exm. Sr. Dr. Fulgêncio Firmino Simões, Presidente desta Província, entregou a administração da mesmo ao Exm. Sr. $2^{\circ}$ Vice-Presidente Brigadeiro Felicíssimo do Espírito Santo em 20 de Fevereiro de 1888. In: Memórias Goianas no 14. Goiânia: Ed. UCG, 2001, p. 184.

24 ASVP: Documentos Avulsos. Relatório do Conselho Particular da Sociedade São Vicente de Paulo enviado ao Conselho Central. Cidade de Goiás, 1888.

25 MAGALHÃES, Sônia Maria de. Alimentação, Saúde e Doenças em Goiás no Século XIX. Tese (Doutorado em História). Franca: UNESP, 2004, 19.

26 Doutrina Cristã era sinônimo de catequese. 
discípulos que para mestres de doutrina"27. É interessante destacar que a ideia inicial foi dos Vicentinos, mas que depois foi encampada pela Igreja. A catequese era um dos principais objetivos da Reforma Ultramontana, e que os padres estrangeiros deveriam se dedicar com afinco, com o objetivo de romanizar o catolicismo afastando-o do seu caráter popular.

Por fim, a visita às prisões e aos hospitais trazia, de acordo com os Vicentinos, "grandes resultados e muitas consolações". Em relação a cadeia $^{28}$ encontravam "os presos entregues a um meio horrível onde só encontram meios de maior perdição que verdadeira correcção". No hospital o quadro não era melhor, com os "enfermos illudidos a uma triste esperança de viver sempre enganados por levianas animações, nunca se lembrão do verdadeiro caminho á seguir":

(...) é assim que vimos duas classes de desgraçados, bem pobres e que não encontram quem lhes leve uma esmola para alimentar o seu espirito, por aqui vemos bem claramente que nem sempre é grande esmola atirarmos simplesmente a sacola do pobre um punhado de ouro, ao passo que seria de grande virtude aquelle que não tendo ouro e que desejando ser util a nossa cara Sociedade se dirigisse a casa do pobre e alli lhe consolasse em sua dôr, que se dirigisse ao cárcere e mostrasse ao criminoso o caminho do arrependimento que se dirigisse finalmente ao hospital e ahi de leito em leito consolasse esses pobres enfermos mostrando-lhes Deus, o medico do corpo e da alma $^{29}$.

Em relação a cadeia e ao hospital, o relato dos Vicentinos encontram paralelo com os relatórios dos Presidentes de Província,

27 ASVP: Documentos Avulsos. Relatório do Conselho Particular da Sociedade São Vicente de Paulo enviado ao Conselho Central.Cidade de Goiás, 1888.

28 O prédio da cadeia, foi construído em 1761, está localizado no largo do Chafariz e desde a década de 1950 transformou-se em Museu das Bandeiras.

29 ASVP: Documentos Avulsos. Relatório do Conselho Particular da Sociedade São Vicente de Paulo enviado ao Conselho Central.Cidade de Goiás, 1888. 
que eram feitos ao final de cada ano. Em 1881, o então Presidente da Província, por exemplo, pretendia transformar a cadeia num local de trabalho a fim de tirar o preso da ociosidade, diminuindo os gastos da sua manutenção, uma vez que é "pessimo em geral, o estado das cadêas da provincia. (...) $\mathrm{O}$ trabalho é também necessário para a hygienne da prizão. Muito conviria crearse tambem na cadêa uma escola nocturna para a instrucção dos sentenciados e dar-lhes igualmente o ensino religioso" ${ }^{30}$. Neste mesmo sentido, o relatório de 1887, revela o estado desses dois estabelecimentos: "Não são boas as condições da cadêa desta capital, sendo para lamentar que o estado da provincia não permitta que decreteis qualquer medida no sentido de melhoral-a, augmentando-a de maneira que possa comportar o numero de presos, que ali se achão actualmente muito acumulados" 31 ; no que tange ao Hospital de Caridade São Pedro de Alcântara, fundado em 1825, "trouxe uma impressão desagradavel. (...) funcciona em um edificio a todos os respeitos inconveniente (...) mudasse as condições precárias de seu hospital, tornando-o capaz de o ser e procurando satisfazer o seu fim, (...) praticando a mais sublime das virtudes - a Charidade" ${ }^{32}$.

Embora citando as péssimas condições sanitárias tanto no hospital quanto na cadeia, os Vicentinos não tinham o objetivo de tentar mudar fisicamente esses locais, e sim mostrar "ao criminoso o caminho do arrependimento", e consolar o doente "mostrando-lhes Deus, o medico do corpo e da alma", como expressam no relatório citado acima.

Quatro anos após a Sociedade São Vicente de Paulo chegar em Goiás, seus confrades idealizaram o que seria a sua maior obra até então, a construção de um asilo para abrigar os pobres, nesse caso, principalmente os indigentes e loucos mansos, que se aglomeravam

30 Relatório apresentado pelo Illm. eExm. Sr. Dr. Aristides de Souza Spinola, ExPresidente da Província, no acto de passar a administração ao Exm. Sr. Vice-Presidente Dr. Theodoro Rodrigues de Moraes em 27 de Dezembro de 1881. In: Memórias Goianas nº 13. Goiânia, Ed. UCG, 2001, p. 129-130.

31 Relatório apresentado a Assembléa Legislativa Provincial de Goyaz pelo Sr. Dr. Fulgêncio Firmino Simões, em 20 de Fevereiro de 1887. In: Memórias Goianas no 14. Goiânia: Ed. UCG, 2001, p. 170.

32 Relatório apresentado a Assembléa Legislativa Provincial de Goyaz pelo Sr. Dr. Fulgêncio Firmino Simões, em 20 de Fevereiro de 1887. In: Memórias Goianas no 14. Goiânia: Ed. UCG, 2001, p. 169. 
pelas ruas, becos e vielas da terra do Anhanguera, "afim de melhor tratá-los em conjunto"33. Embora com o trabalho amplamente reconhecido pela sociedade vilaboense, somente em 1899 a ideia começou a sair do papel, com a aquisição do terreno doado pelo então Intendente Municipal e Vicentino, o médico José Netto de Campos Carneiro $^{34}$, numa região afastada do centro da cidade. A Pedra Fundamental do futuro asilo foi lançada em agosto de 1900, em uma solenidade que contou com a presença da sociedade, dos confrades Vicentinos, de clérigos e do Bispo Diocesano. Durante os dez anos de construção do asilo, foram gastos "39 contos, assim discriminada: esmolas, 14 contos; auxilio da União por meio de loterias, 12 contos de réis; auxilio do governo estadual, 8 contos de réis; auxilio

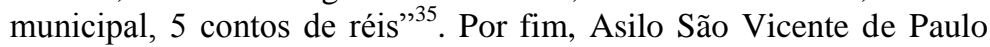
foi inaugurado no dia 25 de Julho de 1909 no subúrbio da Cidade de Goiás, e é o único prédio fora do centro histórico, tombado pelo IPHAN.

Para além do objetivo principal da instituição que era o de “(...) recolher os indigentes e mantel-os; dando-lhes o necessario abrigo, juntamente com o consolo que proporciona a Religião Catholica",36, a construção do asilo, camuflaria, outrossim, sob o discurso da caridade cristã, o saneamento da cidade. Os pobres, mendigos, doentes, velhos, e alienados mentais, que punham em risco a salubridade da então capital, foram colocados numa instituição longe o suficiente da zona urbana. $O$ discurso da caridade que embalou a construção do asilo resolveu, incialmente, um problema que se arrastava há mais de um século, desde o período da tão

33 ASVP: Documentos Avulsos. Histórico da Comunidade do Asilo São Vicente de Paulo - Cidade de Goiás. Cidade de Goiás, s/d, p. 02.

34 José Netto de Campos Carneiro (1857 - 1921). Médico formado na Faculdade de Medicina da Bahia. Foi Deputado Estadual (1892-1894); Secretário de Estado de Instrução e Obras Públicas de Maio a Julho de 1895; Intendente Municipal da Capital por dois mandatos (1899 e 1909); e Secretário de Estado do Interior e Justiça (1913-1914). Foi Diretor do Hospital de Caridade São Pedro de Alcântara. Além do mais foi um Vicentino muito querido pela população vilaboense. Não constituiu família, nem deixou filhos. Em seu testamento doou sua casa e sua fortuna para a instituição de um orfanato, denominado de Orfanato São José.

35 AZEVEDO, Francisco Ferreira dos Santos. Annuario Historico, Geographico e Descriptivo do Estado de Goyaz para 1910. Brasília, SPHAN/8 a DR, 1987, p. 112.

36 ASVP: Documentos Avulsos. "Regulamento do Asylo da Sociedade de S. Vicente de Paulo de Goyaz. Confeccionado pelos Confrades: Desembargador Emilio Francisco Povoa e Dr. Maurílio M. Curado Fleury”. Cidade de Goiás, 1909, p. 02. 
propalada decadência aurífera, na segunda metade do século XVIII. Digo, "inicialmente", porque o Asilo somente não resolveu o problema, as Conferências Vicentinas continuaram com o seu trabalho de prover os pobres que não eram atendidos pelo asilo. Com a construção da instituição aumentou as despesas da Sociedade, que necessitava sempre de mais donativos.

A elite vilaboense, com a construção do asilo, permitiu que a cidade se tornasse mais salubre. Nesse ínterim, até o final do século XIX as teorias miasmáticas dominavam o debate médico; segundo esse princípio, o surto de epidemias de doenças contagiosas era causado em decorrência do estado do ambiente, ou seja, o estado atmosférico envolto pelas más condições sanitárias contribuía para o aparecimento de doenças ${ }^{37}$.

A construção do asilo visto por essa perspectiva representou o empenho de uma elite, que sob o discurso da caridade cristã, empreendeu grandes esforços para higienizar as ruas, becos e vielas de uma cidade insalubre. Localizada num fundo de vale, entrecortada por um rio, cercada por um serra, o que impedia a livre circulação do ar, e, consequentemente uma sensação de bem estar.

Pois bem, o asilo foi construído e o edifício era imponente para a época, possuindo oitenta metros cada lado, em formato de U. Na frente localizava-se a Capela e o Salão da Junta Administrativa do Asilo. No lado esquerdo localizavam-se os dormitórios das Irmãs Dominicanas, vindas diretamente da França para trabalharem na instituição, a cozinha e a rouparia. O lado direito, por sua vez, era dedicado aos alojamentos dos internos.

De acordo com o Regulamento do Asilo São Vicente de Paulo, a Junta Administrativa tinha o objetivo de administrar e angariar recursos para prover a instituição ${ }^{38}$. Era subjugada ao Conselho Particular da Sociedade, que elegia anualmente uma nova Junta, sempre no dia 25 de Julho, data da inauguração do asilo. A Junta Administrativa era composta de um Presidente, um Secretário e

37 ROSEN, George. Uma história da saúde pública. São Paulo: Hucitec/Unesp, 1994, p. 211.

38 ASVP: Documentos Avulsos. "Regulamento do Asylo da Sociedade de S. Vicente de Paulo de Goyaz. Confeccionado pelos Confrades: Desembargador Emilio Francisco Povoa e Dr. Maurilio M. Curado Fleury”. Cidade de Goiás, 1909, p. 03. 
um Tesoureiro, que embora pudessem se reeleger, tal fato nunca ocorreu $^{39}$. Há que se ressaltar que os membros não recebiam salários. Às Irmãs Dominicanas, vindas diretamente da França para trabalhar na instituição, cabia a administração interna. Pela documentação arrolada, até a década de 1960 as Irmãs recebiam salários pelo trabalho realizado na instituição ${ }^{40}$.

Como afirmamos anteriormente, a manutenção do asilo, uma instituição de grande porte no Estado de Goiás, onerava e muito a Sociedade São Vicente de Paulo. À parte do trabalho de cada Conferência, havia a coleta entre os confrades, a contribuição da sociedade, e a promoção de eventos, como quermesses, leilões, espetáculos teatrais, além de outros. Anna Joaquina da Silva Marques, autora de um memorial entre 1881 até 1930, presenciou o esforço da Sociedade São Vicente de Paulo em angariar recursos ${ }^{41}$. Na noite de $1^{\circ}$ fevereiro de 1886 “(...) houveTheatro em beneficio de S. Vicente de Paula. (Vingança de 1 escravo, e a comedia o morto embargado) esteve $\mathrm{m}^{\text {to }}$ concorrido nós não fomos" ${ }^{\text {"42 }}$. No dia 23 de julho de 1886 , "eu Nhola e Lili fomos a novena de S. Vicente de Paula. Houve Leilão"43. Mais adiante, no dia 21 de julho de 1889 "houve leilão de S. Vicente de Paula houve $\mathrm{m}^{\text {tas }}$ prendas q' forão arrematadas" 44 . Por fim, em 8 de dezembro de 1889 "teve bailão de S. Vincente de Paula

39 ASVP: Documentos Avulsos. Nomes dos confrades da Sociedade de S. Vicente de Paulo que tem sido eleitos para administrar o Asilo. Cidade de Goiás, 1966.

40 ASVP: Documentos Avulsos. "Regulamento do Asylo da Sociedade de S. Vicente de Paulo de Goyaz. Confeccionado pelos Confrades: Desembargador Emilio Francisco Povoa e Dr. Maurilio M. Curado Fleury”. Cidade de Goiás, 1909, p. 03 Em 2015 o nome da instituição foi alterado, de asilo para "lar". Atualmente conta com sessenta e cinco internos, sob os cuidados das Irmãs Dominicanas, que administram a instituição sozinhas, sem a divisão com os vicentinos. Assim como no início, a maioria dos asilados constituem em idosos com problemas mentais.

41 Sobre Anna Joaquina da Silva Marques ver o interessante estudo de: CARVALHO, Euzébio Fernandes de. O Rosário de Aninha: os sentidos da devoção rosarina na escritura de Anna Joaquina Marques. Cidade de Goiás, 1881-1930). Dissertação (Mestrado em História Universidade Federal de Goiás). Goiânia, 2008.

42 Instituto de Pesquisas e Estudos Históricos do Brasil Central. Memorial de Lembranças de Anna Joaquina da Silva Marques. (mimeo). Cidade de Goiás. 1881-1899. v. 1, 2006, p. 79.

43 Instituto de Pesquisas e Estudos Históricos do Brasil Central. Memorial de Lembranças de Anna Joaquina da Silva Marques. (mimeo). Cidade de Goiás. 1881-1899. v. 1, 2006, p. 86.

44 Instituto de Pesquisas e Estudos Históricos do Brasil Central. Memorial de Lembranças de Anna Joaquina da Silva Marques. (mimeo). Cidade de Goiás. 1881-1899. v. 1, 2006, p. 120 . 
p. ${ }^{\text {a }}$ q' o rezultado fosse o din. ${ }^{\circ}$ distribuido com os pobres. Nhola Lili e Eu offerecem os objectos, . $^{\text {a }}$ esse fim" ${ }^{45}$.

O General Pedro Cordolino Ferreira de Azevedo (18841958), por exemplo, um vilaboense radicado no Rio de Janeiro, escreveu na obra Terra distante suas impressões de Goiás quando por aqui voltou a passeio, no inicio da década de 1920, ao observar os esforços da Sociedade São Vicente de Paulo observou a respeito dos recursos gastos pela instituição "a energia, tenacidade e abnegação de que só são capazes as almas puras e devotadas ao sacrificio"46.

Por outro lado, a Sociedade São Vicente de Paulo modificou a relação entre o individuo e os pobres em Goiás, principalmente por meio das esmolas. Entendemos por esmola, de acordo com um dicionário de 1832, como aquilo "que se dá ao necessitado"47. Por meio do ato de distribuir esmolas, a piedade para com os pobres demonstrava "uma forma de expressar devoção para com Deus"48, uma vez que elas respeitavam a dignidade pessoal do pobre ${ }^{49}$. Entretanto, com o surgimento da Sociedade São Vicente de Paulo, o significado do ato de distribuir esmolas mudou. Por meio da referida Sociedade, o indivíduo não precisava mais dar ao necessitado o dinheiro para conseguir as benesses dos céus; a esmola passou a ser doada à própria Sociedade, a quem caberia a missão de geri-la.

O discurso de que a Sociedade São Vicente de Paulo era embasada por fortes laços caritativos cristãos, que envolvia o amor ao próximo e de abnegação, perpassou o tempo, embora haja várias camadas subjetivas de interpretação a respeito dessa caridade tipicamente goiana, um misto de assistencialismo, filantropia e caridade cristã.

45 Instituto de Pesquisas e Estudos Históricos do Brasil Central. Memorial de Lembranças de Anna Joaquina da Silva Marques. (mimeo). Cidade de Goiás. 1881-1899. v. 1, 2006, p. 125.

46 AZEVEDO, Cordolino de. Terra Distante (Impressões de Goyaz). Rio de Janeiro: s/e, 1925, p. 95.

47 PINTO, Luiz Maria da Silva. Diccionario da Lingua Brasileira. 1832. Edição FacSimilar. Goiânia: Sociedade Goiana de Cultura, Instituto de Pesquisas e Estudos Histórico do Brasil Central, Centro de Cultura Goiana, 1996.

48 FRAGA FILHO, Walter. Mendigos, Moleques e Vadios na Bahia do Século XIX. São Paulo, SP/Salvador, BA: Editora Hucitec/EDUFBA, 1996, 35.

49 MOLLAT, Michel. Os Pobres na Idade Média. Rio de Janeiro: Campos, 1989, p. 151. 
O que exemplifica a filantropia em Goias foi o Orfanato criado pelo Dr. Netto considerado pela antiga capital de Goias como o "pai dos pobres".

\section{O Orfanato São José}

José Netto de Campos Carneiro, filho do major João Netto Cerqueira Leão e Maria Franscisca Cerqueira Leão, católico, nunca foi casado ou teve filhos. Formou-se em medicina em 1855 na Bahia, retornando para Goiás onde exerceu por toda vida sua profissão. $\mathrm{O}$ que o diferenciou de outros médicos foi sua dedicação no atendimento para ricos e pobres. Facilmente encontramos na literatura goiana ou nos jornais, elogios perante sua atuação como médico e a sua benevolência, sendo chamado popularmente como o "pai dos pobres". Quando faleceu, deixou escrito em seu testamento, o desejo para construção de um orfanato para meninas mantido por seus bens, rendas de alugueis dos inúmeros imóveis espalhados pela cidade de Goiás. Faz-se importante analisar sua trajetória como médico e homem prestigiado na cidade. Indagando a imagem construída de pai dos pobres, compreendendo assim, seu real sentido de dedicação aos mais necessitados: a filantropia.

Consideramos a filantropia como virtude social de uma prevenção à miséria e que se distância da caridade ligada à religião. Por vezes a filantropia influenciou ações individualizadas de médicos que seguiam um princípio nacional "Partilhavam igualmente a consciência, herdada dos iluministas, de que os principais problemas de saúde advinham da precariedade, quando não mesmo da miséria da maioria da população" ${ }^{50}$ Sendo assim, observamos na obra "Das febres em Goyaz", escrita pelo médico José Netto, a influência do designo da filantropia em seu discurso,

50ABREU, Laurinda. 'Prefácio'. IN: SANGLARD, Gizele [et al] Filantropos da Nação: sociedade, saúde e assistência no Brasil e em Portugal. Rio de Janeiro: Editora FGV, 2015, p. $7-12$. 
“(...) procurarei entreter com o benévolo leitor que não teme-se embrenhar-se nas ingratas regiões das moléstias, uma palestra sobre o impaludismo em suas diversas manifestações clinicas, e se adopto o termo febres de preferência ao de paludismo ou impaludismo é por ser aquelle o mais vulgarmente conhecido, e não tendo eu a veleidade de escrever para os mestres, mas dirigindo-me simplismente áquelles que longe dos recursos da sciencia soffrem as conseqüências d'esse protêo, ao qual pagam annualmente um pesado tributo, encararei o assumpto sob um ponto de vista todo pratico, baseado ás mais das vezes nos pequenos conhecimentos que adquiri no exercício clinico por de 10 annos.",51

O texto "Das Febres em Goyaz" escrito por José Netto, publicado em 1897 em Porto, no formato de folhetos, dedicado a seus amigos, tem como objetivo segundo o médico, contribuir para o combate do impaludismo ${ }^{52}$ em Goiás, doença considerada endemia na capital goiana. Embora trate de uma doença, ou seja, de um assunto científico, José Netto diz estar escrevendo para aqueles que sofrem as consequências do que ele denomina de "protêo". Observamos dois sentidos em seu discurso: o primeiro refere-se que o conhecimento e a

51 CARNEIRO, José Netto de Campos. Das Febres em Goyaz. Porto: Tip. A vapor de Arthur José de Sousa \& Irmão, 1897, introdução.

52 A malária ou impaludismo é uma doença infecciosa, não contagiosa e de evolução crônica, com manifestações episódicas de caráter agudo. Provavelmente é a doença parasitária mais antiga, conhecida na Antigüidade como febre intermitente. Devido ao seu caráter endêmico, foi responsável por tantas mortes quanto foram as próprias guerras em vários períodos da história. Existem quatro formas de malária humana, identificadas através de exames de laboratório, conforme os seguintes agentes infecciosos encontrados no sangue do paciente: Plasmodium falciparum, causador da forma mais grave da doença, Plasmodium vivax, Plasmodium malariae e Plasmodium ovale. Estes três últimos normalmente não provocam morte. Os sintomas da malária na sua forma aguda em geral no indivíduo não imune são: calafrios fortes, acompanhados de dor de cabeça, náusea e sudorese profunda. Estes sintomas se repetem em ciclos diários, em dias alternados ou a cada três dias e podem durar de uma semana a um mês ou mais. As recaídas podem acontecer a intervalos regulares no caso do P. vivax, podendo persistir por até 50 anos no caso do plasmódio malariae. Disponivel em: http://www.fiocruz.br/bibmang/cgi/cgilua.exe/sys/start.htm?infoid=104\&sid=106. Mais sobre o tema: BENENSON, A. S. El control de las enfermidades transmisibles en el hombre. 14 ed. Washington : Ed. Organización Panamericana de la Salud, 1987. (Publicacción Científica; 507); SCHREIBER, W. \& MATHYS, F. K. Infectio. São Paulo: Roche, 1991.VERONESI, Ricardo. Doenças infecciosas e parasitárias. 8.ed. Rio de Janeiro: Guanabara Koogan, 1991, Disponivel em http://www.cpqrr.fiocruz.br/informacao_em_saude/CICT/malaria/malaria.htm 
prevenção desta doença deve ser dirigida para a população, sendo seu propósito educá-la; no entanto, o outro sentido nos inquieta. Escrevendo para pessoas comuns, ou que não tem o conhecimento adequado para interpretar um texto com linguagem carregada de termos científicos, seu objetivo não poderia ser apenas instruir, mas também divulgar seu exercício como médico no meio acadêmico. Em outro momento diz,

Se fora meu intento fazer uma dissertação completa do conjuncto dos phenomenos mórbidos que phatologia consigna sob o nome de impaludismo, e não escrever modestas linhas sobre febres, indubitavelmente o meu dever conduzir-me-ia a tratar de uma parte importante do assumpto a anatomia pathologica; em tal caso teria de recorrer aos indispensáveis subsídios trazidos pelo escalpello de mãos dadas com o microscópio, e inveredar com o tolerante leitor por uma região interessantíssima, sem duvida para o homem da sciencia, porém que longe de auxiliar-nos, traz-no-ia a confusão e quiçá o tédio ${ }^{53}$.

Neste outro trecho, o médico reforça o intuito da sua escrita e porque deixa de fazer certas abordagens. É interessante perceber a construção e uma intencionalidade do autor, em reforçar sua preocupação com a população, tecendo uma sutil crítica "ao homem da sciencia" e o uso de aparelhos como o microscópio.

Durante sua permanência na capital goiana, Dr. Netto assumiu a responsabilidade de direção no Hospital São Pedro de Alcântara e ocupou por diversas vezes cargos públicos como intendente municipal e inspetor do posto de higiene. Conciliando a medicina e política, esteve sempre associado às obras de assistência na cidade como abordado anteriormente. Na fundação do Asilo São Vicente de Paulo, por exemplo, contribuiu com a doação do terreno em 1889 e posteriormente em 1909 assinou a lei que autorizava seu Arthur José de Sousa \& Irmão, 1897, p.13. 
funcionamento. Sobre o Asilo São Vicente é importante destacar que nas duas ocasiões, de doação do terreno e inauguração, Dr.Netto ocupava o cargo de intendente municipal, corroborando com o pressuposto de que o mesmo esteve à frente para a existência estabelecimento na cidade e das questões assistencialistas.

Diante de tantos feitos do médico, apontamos outras obras realizadas enquanto intendente municipal na cidade de Goiás: construção de um cais às margens do rio vermelho, pela lei municipal $n^{\circ} 226$ e um chafariz na rua quinze de novembro ${ }^{54}$. Como médico, segundo Moraes ${ }^{55}$, Dr. Netto possuía autorização do governo para realizar procedimentos cirúrgicos, considerado pela autora o primeiro cirurgião de Goiás no período da primeira república. Sendo o único cirurgião na cidade do seu tempo, seu prestígio perante a sociedade se elevava. Pessoas que por vezes se encontravam a mercê de tão poucos profissionais qualificados.

Reconhecemos José Netto de Campos Carneiro, como um homem da ciência, por sua profissão e dedicação à cura das diferentes doenças que assolavam a população vilaboense. Embora parte importante para o campo científico de Goiás, afirmava que a ciência pouco contribuía para a qualidade de vida das pessoas. Seu nome era ligado facilmente aos mais necessitados. Para Ofélia Sócrates que viveu em Goiás no mesmo tempo do médico afirma,

Era adorado geralmente, apesar de seus modos um tanto bruscos, que, no entanto, não encobriam a bondade excessiva de seu coração. (...) Todos os anos, por ocasião de seu aniversário, recebia manifestações de todas as classes sociais, sendo tradicionais os bailes do dia 27 de fevereiro. Gostava imensamente de flores, trazendo

54 BUENO, Jerônimo Carvalho. História da medicina em Goiás. Goiânia: edição do autor, 1979 , p.49.

55 MORAES, Maria Augusta de Sant`Anna. Dos primeiros tempos da saúde pública em Goiás à Faculdade de Medicina. Goiânia: Canône Editoria. 2012, p.137. 
sempre uma à lapela. Foi Dr.Netto um grande apostolo da caridade e amor ao próximo ${ }^{56}$

Estar sempre associado a atos de caridade não excluiu a revelação sobre sua personalidade, colocada pela autora como "modos um tanto bruscos". Sendo assim fica uma dúvida, visto como uma pessoa rude como poderia ainda sim ter "bondade excessiva"? Rosarita Fleury também coloca a questão do temperamento do médico José Netto, "foi um abnegado médico goiano, de temperamento áspero, por sua franqueza muitas vezes rude, mas solidário" ${ }^{, 57}$ É interessante observar que as duas autoras colocam a questão da personalidade do médico primeiro e posteriormente suas ações benevolentes. Como que seus atos como médicos compensassem sua personalidade difícil. Seu aniversário era comemorado por toda cidade, uma festa que perdurava por todo o dia, recebendo homenagens de todos os vilaboenses, um grande acontecimento como Ondina Albernaz escreveu "O acontecimento social mais importante ocorria a 27 de fevereiro. Grande data, grandes comemorações, a cidade em festa, aniversariava o grande escapulário, discípulo de Hipócrates, Jose Netto de Campos Carneiro" ${ }^{\text {58 }}$. Ser um dos poucos médicos da Cidade de Goiás coloca Dr. Netto em uma posição de prestígio. Embora não se tratava apenas de assumir um papel - o de médico -, mas de estar constantemente ligado as questões públicas da população local, elevando assim sua relação com a sociedade. Refletindo sobre sua trajetória e da sua atuação não apenas no exercício do seu oficio, notamos que o médico exercia uma importante influência sobre a população da cidade. Sua posição social, todavia, poderia contribuir para estabelecer comportamentos e mudanças na sociedade.

56 MONTEIRO, Ofélia Sócrates do Nascimento. Goiaz. Coração do Brasil. Brasília. Senado Federal, 1983, p.186-187.

57 TEIXEIRA, Maria Elizabeth Fleury. Rosarita Fleury.Minha mãe. Goiânia: editora Kelps, 2014, p.43.

58 ALBERNAZ, Ondina de Bastos. Reminiscências. Goiânia: editora Kelps, 1992, p. 21 . 
José Netto de Campos Carneiro faleceu no ano de 1921, em decorrência de úlcera estomacal descoberta há vários anos. Viajou diversas vezes para Europa em busca de novos tratamentos para sua doença. Sabendo da gravidade de seu estado, preparou-se para morte. Escreveu seu testamento de próprio punho e recolheu-se em sua fazenda Conceição para passar seus últimos dias.

Faleceu, porém, antes da chegar às proximidades da fazenda da 'Quinta', conduzido em bangüê" 59 . "E por moças de sua terra foi conduzido, da porta do cemitério ao túmulo". 60

Tal acontecimento expressa certa romantização por parte dos memorialistas, como se a população atendida por ele o conduzisse até seu leito de morte em forma de agradecimento por sua dedicação. Contudo não fora encontrado nos jornais notas sobre seu falecimento, apenas sobre sua doença e seu recolhimento na Fazenda Conceição. Tal fato pode demonstrar que o filantropo Dr. Netto não conquistara admiração de todos, pois outras notas de falecimento foram encontradas nos dias próximos à sua morte, de pessoas com menor posição social. Os proprietários dos jornais locais foram pessoas de prestígio na cidade, médicos, políticos e bacharéis em direito. A não divulgação da sua morte e seu enterro nos acirra a acreditar que havia para além de problemas pessoais, como aventa a historiadora Sanglard, ao discorrer sobre a disputa entre filantropos.

O testamento do Dr. Jose Netto, escrito um ano antes do seu falecimento, descreve suas principais preocupações à frente sua morte. Diante de uma divisão prática dos bens, entre irmãos, sobrinhos e afilhados, houve também um equivalente patrimônio designado para caridade. Os instrumentos cirúrgicos, doados ao Hospital São Pedro, apólices de dívida pública para Seminário

59 BUENO, Jerônimo Carvalho. História da medicina em Goiás. Goiânia: edição do autor, 1979, p.50.

60 ALBERNAZ, Ondina de Bastos. Reminiscência. Goiânia: editora Kelps, 1992, p.187. 
Diocesano "para ser mantido e educado um ou mais meninos pobres" ${ }^{61}$, estabelecimento onde o José Netto realizou seus estudos iniciais, antes de decidir cursar medicina. Não localizamos no testamento uma descrição do seu velório, que ficou a critério do seu sobrinho. $\mathrm{O}$ único momento no documento que houve uma preocupação com sua crença encontra-se no último ponto do testamento, quando solicita "Todos os anos no aniversário da minha morte será celebrado pelo Asylo uma missa por minha alma e distribuir aos pobres asylados quantia nunca inferior a cem mil reis" ${ }^{\prime 62}$. Mesmo sendo considerado um homem de fé e caridoso, houve uma preocupação considerável a respeito da sua alma, que foi velada por missas anuais e distribuição de esmolas aos pobres, conforme prescritos no testamento. Uma atitude pouco comum para o período, mas muito presente no século XVIII, o que nos remete a supor que seu pedido não possuiu apenas sentido religioso, mas juntamente com o projetar da figura de homem bom e benevolente.

A doação de bens para a fundação do asilo para meninas desvalidas, conforme desejo do Dr. Netto, foi um fator de importante relevância após sua morte, significando posteriormente como seu maior ato de caridade. Todo remanescente, ou seja, os bens ainda não declarados no testamento,

“(...) será aplicado na manutenção de um modesto Asylo
para órfãs desvalidas nesta Cidade de Goiás, na casa que
resido, à Rua da Penha, que será para esse fim adaptada,
conservando-se as suas formas gerais, tirando o
necessário para essa instalação tudo mais será convertido
em renda para o custeio do mesmo. ${ }^{3}$,

Não havia em Goiás, nesse período, um orfanato ou asilo que atendesse meninas órfãs. Essa foi uma questão discutida entre

61 Arquivo Lar São José. Certidão de testamento, José Netto de Campos Carneiro, 1920, Cidade de Goiás.

62 idem

63 idem 
algumas autoridades, incluindo o próprio Dr. Netto antes de seu falecimento. Observamos em ata da junta administrativa do Asilo São Vicente de Paulo, a relevante importância de criar na cidade um estabelecimento para crianças,

(...) a creação de um orphanato, oxalá que a última vontade do grande amigo desta casa, de amigo e pai dos pobres, o distinctíssimo medico Jose Netto Campos Carneiro, se converta em realidade, a fim de que, em breve, possamos ver na nossa Capital um abrigo seguro para a infância desvalida. Precisamos, nós vicentinos, tomar isto a peito, trabalhar e pedir a Deus que tão grandiosa obra se torne uma certeza, precisamos olhar pela infância desamparada, que sem arrimo anda por essas ruas e...é custoso dezel-o, nas doentias cellas da nossa cadeia. Trabalhemos que o nosso trabalho não será sem fructo. Todos os estabelecimentos de caridade são fundados a custa de sacrifícios, sem outro capital que não seja esperança em Deus e nas almas grandes e generosas. Todos virão no encontro desta grandiosa e generosa. Todos virão no encontro desta grandiosa e patriótica empresa $^{64}$

Sendo assim, por essa proximidade com o asilo, o médico compreendia os problemas dos quais a instituição passava, pois era até o ano de 1921 o local onde eram recolhidas ou enviadas pelo Juiz de Orphãs da capital as crianças. Crianças órfãs, doentes, em situação de abandono ou desamparadas, dividiam espaços com adultos e idosos. Em número, as crianças desvalidas chegaram a representar $25 \%$ da população do Asilo São Vicente de Paulo, representando um elevado custo para a instituição ${ }^{65}$.

de 1922 .

64 ASVP. Relatório da Junta Admnistrativa do Asilo São Vicente de Paulo, 23 de julho

65 SOUZA, Rildo Bento de. Pobreza, doenças e caridade em Goiás: uma análise do Asilo São Vicente de Paulo (1909-1935). Jundiaí-SP: Paco Editorial, 2014, p. 102. 
Havia uma necessidade emergente para a criação de um abrigo para a infância desvalida na capital, porém foi inaugurado um orfanato, apenas para crianças do sexo feminino, saudáveis. "O fim do Orfanato é a manutenção e educação moral, religiosa e doméstica de órfãs pobres, especialmente dessa capital, que se acharem nas condições previstas nesse estatuto" " ${ }^{66}$ A escolha por meninas, órfãs e saudáveis, não foi aleatória e possuía dois motivos. O primeiro era o da assistência, com bases científicas, ou seja, um atendimento que propiciasse a disciplinarização dessas meninas para o trabalho doméstico. Outro motivo estava mais ligado as questões de uma norma existente "Todo um discurso moralista e filantrópico acena para ela, de vários pontos do social, com o perigo da prostituição e da perdição diante do menor deslize" ${ }^{\circ 7}$. Amparar uma menina, e educála, tinha significado que estava além do sentido de acolher, mas também de "salvá-la" dos perigos e vicissitudes da prostituição. Assim, a grande preocupação era com as crianças femininas saudáveis e não as doentes (essas continuaram no Asilo), mas as saudáveis estariam aptas para exercer a função de doméstica e do lar, isto é, preparando-as nos preceitos moralistas cristão.

Os meninos pobres eram encaminhados para a Escola de Aprendizes e Artífices de Goiás, criado por ordem federal, desde o início da república no Brasil, teve como objetivo "moldar" aqueles que eram chamados de desfavorecidos, diante de um novo olhar sobre o trabalho infantil. Uniu-se a educação e a força de trabalho com o objetivo de formar futuros cidadãos civilizados e aptos para o trabalho. Havia um interesse por parte das autoridades no combate a prática de vadiagem. Segundo Rizzini “(...) o combate ao estilo "vida vagabunda" deve ficar bem entendido como um gesto de contenção a um ato identificado como de insubordinação, ou seja, o individuo, embora apto, recusava-se a trabalhar, o que, em outras palavras, significava uma recusa em servir sua pátria, ${ }^{, 68}$

66 Arquivo Lar São José. Estatuto do Orphanato de São José, 22 de novembro de 1922, Cidade de Goiás.

67 RAGO, Margareth. Do cabaré ao lar. A utopia da cidade disciplinar e a resistência anarquista. Brasil 1890-1930. $4^{\circ}$ edição. São Paulo/Rio de Janeiro, Paz \& Terra, 2014, p.89.

68 RIZZINI, Irene. O século perdido. Raízes históricas das políticas públicas para a infância no Brasil. $3^{\mathrm{a}}$ edição. São Paulo: Cortez, 2011, p.56 
O destino que se manifestou para o Orfanato São José, atendeu primeiramente ao pedido feito no testamento por José Netto, referência para a construção do estatuto que estabeleceu as regras e organização do estabelecimento. Chama-nos atenção para uma exigência: que o asilo funcionasse na sua casa, sendo adaptado, mantendo suas formas gerais. Deixar grande parte da sua herança para um propósito e exigir que a instituição funcionasse na sua residência, demonstra uma preocupação do médico com sua imagem mesmo após sua morte.

Em ata da reunião da junta administrativa, em 1944 ficou decidido que "(...) no dia 27 de fevereiro as órfãs deveriam levar flores ao mausoléu do Dr. Netto" "69. Já no mês de março consta que foram realizadas comemorações do aniversário Dr. Netto. E essas comemorações ocorrem ano após anos sempre no mês do seu aniversário, conforme constatamos nas atas de reunião da junta administrativa. Em 1956, quase trinta anos após sua morte, uma reportagem enaltece a imagem do médico o denominando de "Goiano Ilustre" ${ }^{70}$. O texto traz uma breve biografia do médico e destaca "Com o coração sempre voltado para os humildes", sobre seus feitos e ainda completa sobre o orfanato,"Dono de considerável fortuna, legou esse monte a uma instituição que viesse cuidar das órfãs abandonadas de Goiás. Essa instituição é hoje o 'Orfanato de São José', estabelecimento de bases filantrópicos que eleva Goiás no conceito das cidades civilizadas".

É interessante notar na fala do estudante o reconhecimento do orfanato como uma instituição filantrópica. O que percebemos nos documentos, é que o orfanato ofertava para as meninas além do acolhimento, educação primária, atendimento médico e dentário, além de aulas de bordado e costura. A oferta na instituição de todos esses serviços foi constantemente encontrada nos pedidos de subvenção enviados aos representantes do município, estado e governo federal. A apresentação da instituição situava-se como um estabelecimento privado, que atendia ao um bem púbico e por isso requeria verbas que

69 Arquivo Lar São José. Reunião da Junta administrativa do Orfanato São José. Ata do dia 20 de fevereiro de 1944.

70 Fundação Frei Simão Dorvi. Jornal “O Univresitário”, maio de 1955. 
auxiliassem seu funcionamento. Todavia, encontramos com frequência nos pedidos, a identificação do orfanato como uma instituição de ordem caritativa, ou até mesmo, como "Casa de caridade". No entanto, compreendemos o Orfanato São José como uma instituição filantrópica, por conta dos indícios apresentados nos documentos.

Um desses indícios seria o próprio Estatuto do Orfanato de São José, no qual localizamos objetivos claramente definidos. No artigo terceiro está escrito “(...) o fim do Orfanato é a manutenção e a educação moral, religiosa e doméstica de órphãs pobres" ${ }^{71}$. A mendicidade, a oferta da esmola em dinheiro agora condenada, proferiu uma forma de caridade muito próxima a filantropia, pois reconhece a importância de auxílio que modifica a condição social da pessoa. Essa tentativa feita por meio dos discursos, de constituir um padrão comportamental a ser seguido é denominada pela autora Mestriner, de uma filantropia disciplinadora, “(...) o interesse colocado nas práticas assistencialistas nesse momento é a recuperação de meninos e meninas com vista a prepará-los para sua futura incorporação à força de trabalho"72

Em síntese o objetivo do Orfanato São José, foi uma instituição com fins filantrópicos, que abrigava meninas órfãs com boa saúde e que recebeu da instituição uma formação (doméstica e educação primária), sempre aliadas a princípios religiosos e científicos atendendo ao desejo do seu fundador. Apesar de ser a única instituição na cidade que atendia a meninas desvalidas, seu reconhecimento por parte das autoridades políticas só ocorreu após os anos de 1950 com elevação da subvenção anual concedida pelo município prevista em lei.

71 Arquivo Lar São José. Estatuto do Orphanato de São José, 22 de novembro de 1922, Cidade de Goiás.

72 MESTRINER, Maria Luiza. O Estado entre a filantropia e assistência social. $4^{\circ}$ edição. São Paulo: Cortez, 2008, p.94. 


\section{Considerações Finais}

No sertão dos Guayazes, diante de tantas dificuldades desde sua ocupação por reinóis excluídos pelo morgadio, degredados não somente por "Eva", mas em todo o Antigo Regime, paulistas falidos, africanos e ladinos escravizados instalou-se desde o inicio a família franciscana para cuidar do protagonismo espiritual dos habitantes.

A insegurança provocada pelos indigenas, o clima adverso, com seca e chuvas abundantes e a extensão territorial e, nessa mesma medida, o fervor piedoso da contrição e o desejo de salvação; ora, nos ataques dos "gentio", em periodo de carestia e alta de preço, epidemias, em tempos de crises por falta de esperança sobretudo até o oitocentos, as populações deambulavam em busca de tranquilidade em autênticos cortejos penitenciais. A mentalidade popular nesses momentos apareciam como aviso ou castigo das forças sobrenaturais, face aos desvarios e corrupção dos homens. Urgia, por isso, apaziguar a ira de Deus e esconjurar as forças maléficas. Espontaneamente, ou lideradas por padres franciscanos e/ou dominicanos que "eram sempre nestas ocasiões os primeiros, os quaes fizeram huma solemne procissão, para a qual concorreram todos os habitantes desta cidade com muita devoção; e foi a N. Senhora da Boa Morte, e se recolheu com mais de duas horas de noute, e depois de recolhida houve huma pratica espiritual, com açoite muito comprido... Houve mais em toda a cidade varias procissões, e pregações e disciplinas. ${ }^{, 73}$

Poderiamos sempre pensar que desde o inicio dos tempos sempre foi a caridade e não o verbo. Não a esperança no céu tão inascessivel e sim, o medo em não atingir o purgatório. A verdadeira caridade não esta na esmola que damos e sim no amor e na assistencia fraterna que temos uns com os outros. Os portões do paraiso abrir-sea com a máxima: “ Amar ao próximo como a si mesmo, fazei para os

73 No relato: "Fizeram-se muitas procissões com vários gêneros de penitencias, para que Deus aplaque sua ira" Biblioteca de Évora, Códice CIV / 1-14. Ou como diz o relato da Biblioteca da Ajuda, Papéis ultramarinos, mç. 1. Cf.: Cf. ENES, Maria Fernanda, "A vida conventual nos Açores: regalismo e secularização" in Lusitana Sacra, Revista do CEHR / Univ. Católica Portuguesa, $2^{\circ}$ série, (ii), 1999, pp. 323-351. 
outros o que queriamos que os outros fizessemos por nós". (São Mateus, cap. XVIII, ver. de 23 a 35)

Faz-se oportuno destacar que das irmandades setecentistas às irmandades ou conferencias vicentinas, a caridade praticada em fins do século XIX, era "o que se dá ao necessitado" "74. Por meio do ato de distribuir esmolas, a piedade para com os pobres se demonstrava como "uma forma de expressar devoção para com Deus" (FRAGA FILHO, 1996, p.35). Por conseguinte, MOLLAT apontou que a doação de esmolas em dinheiro respeitava a dignidade pessoal do pobre (1989, p. 150-151). Entretanto, defendemos que com o surgimento da Sociedade São Vicente de Paulo, a significação do ato de distribuir esmolas mudou. Por meio da referida sociedade o indivíduo não precisava mais dar ao necessitado o dinheiro para conseguir as benesses dos céus; a esmola passou a ser revertida para a própria Sociedade, a quem caberia a missão de geri-la. A caridade ganha um sentido puramente exibicionista o que em meados do século XX, será amplamente divulgada e aceita por todos e pelo Estado. A filantropia e os filantropos responsabilizar-se-ão em preparar o calçamento para a estrada que poderá não levar ao "Pai" que está nos Céus...mas indicará o caminho ao poder...ao sucesso e ao reconhecimento dos homens imbuídos de boa vontade!

RECEBIDO EM: 01/03/2017 APROVADO EM: 01/06/2017

74 PINTO, Luiz Maria da Silva. Diccionario da Lingua Brasileira. 1832. Goiânia: Sociedade Goiana de Cultura, Instituto de Pesquisas e Estudos Histórico do Brasil Central, Centro de Cultura Goiana, 1996. 